\title{
Justicias, pluralismo y derecho socialmente existente *
}

\section{Justice, pluralism an the valid laws of today}

\begin{abstract}
Rosembert Ariza Santamaría **
Aquellos que rechazan mis análisis [por lo peculiar de los resultados] no pueden ver que lo que realmente importa en ellos no son tanto los resultados sustantivos en sí mismos como el proceso mediante el que se obtienen. Las "teorías" son programas de investigación que no van dirigidas al "debate teórico", sino a una utilización práctica que las rechaza o las generaliza o, aún mejor, especifica y diferencia su pretensión de universalidad.

Pierre Bourdieu

Fecha de recepción: 12 de febrero de 2008 Fecha de aprobación: 17 de abril de 2008

\section{Resumen}

El artículo pretende cuestionar las llamadas justicias en los escenarios sociales, en los que se aplican, con el propósito de establecer si configuran un campo "jurídico" distinto al formal estatal. También se quiere dilucidar los alcances de estas prácticas (maneras) de justicia en el discurso actual del Derecho, mirada que se hace, por supuesto, desde las corrientes críticas.
\end{abstract}

\section{Palabras clave}

Justicia, pluralismo, derecho, campo jurídico, formalismo, sistema informal de justicia.

Este texto recoge elementos de varios capítulos de la tesis doctoral que el autor adelanta actualmente y que culminará durante el presente año, intitulada Justicia comunitaria, Justicia Indígena y Justicia informal en Colombia: el campo jurídico de las prácticas sociales y culturales de justicia.

Actualización en enero del 2021, por solicitud de Raquel Yrigoyen Fajardo y Rosembert Ariza Santamaría.

** Abogado, docente investigador de la Facultad de Derecho de la Universidad Santo Tomás e integrante del grupo de investigación Derecho y Sociedad (categoría A de Colciencias). Candidato a Doctor en Sociología Jurídica e Instituciones Políticas de la Universidad Externado de Colombia. Correo electrónico: arosembert@gmail.com 


\section{Abstract}

This work try to put question the calls "justices" in the social scene where they are applied, with the goal of to establish if the questions form legal field different that state legal field. The article, also wants to explain the scopes of this practices of justice in the current discourse of the law, look that is done, of course, from the critical trends.

\section{Key words}

justice, pluralism, law, legal field, formalism, informal system of justice.

\section{INTRODUCCIÓN}

El derecho socialmente existente es aquel que se da como parte de las relaciones y de los conflictos que se resuelven en espacios sociales y no aquel que los doctos embalsaman en la retórica técnica y que es incomprensible para un ciudadano del común. No es democrático que las elites jurídicas construyan en su torre de marfil mensajes criptográficos para la sociedad que pretenden ordenar. Este distanciamiento permite que ebullan múltiples discursos jurídicos, que no posan al sanedrín del saber especializado, sino que por el contrario, elaboren simples soluciones a problemas complejos que se validan en la comprensión colectiva.

La sociedad se autorregula y propende a soluciones efectivas a sus conflictos; el Derecho cada día se enaltece con los grandes conglomerados económicos y se distancia radicalmente de la sociedad. Esto conlleva la aparición de otro Derecho que tiene un acervo social y cultural cercano a la vida cotidiana y a los problemas reales, y no a las formulaciones metateóricas del campo jurídico; desconocer la capacidad regulativa de la sociedad puede llevar a una encrucijada en la cual el orden sea de facto cuando lo legal es abrumadoramente ilegítimo.

Las comunidades marginales, los grupos minoritarios, los pueblos ancestrales y los excluidos del derecho de acceso a la justicia configuran su propia justicia: una justicia justa y no legal, que predominantemente regula las relaciones cotidianas y le da sentido a unas prácticas comprensibles e integradas en su medio, por esto son cada vez más aceptadas y desarrolladas por los profanadores del derecho, que no son otros que los hacedores de lo justo en comunidad. El campo de las prácticas sociales y culturales de justicia no surge como reactivo a la ausencia del Estado, lo que se encuentra en estas justicias es un emerger del pasado, de la historia desconocida y de la inconmensurable necesidad de autodeterminación social de los procesos locales.

Entre una justicia por ausencia del Estado y una justicia complementaria a la del orden legal imperante se mueve una posibilidad que no sea ni lo uno, ni lo otro, lo que las comunidades locales y los grupos étnicos pretenden no es ni sustituir ni complementar la administración formal de justicia, sólo pretenden convivir armónicamente con sus congéneres, con el medio ambiente y con su mundo espiritual; estas relaciones no están en el campo de lo material ni lo racional.

En cuanto a lo teórico, desde hace unas décadas distintas disciplinas como la Filosofía, la Sociología, la Antropología y el propio Derecho han estado trabajando conceptos y categorías de justicia de manera indeterminada; esto ha llevado a una suerte de construcciones de retóricas, discursos académicos y tecnocráticos que, de manera pragmática, soslayan el debate de fondo y el rigor de lo que acontece en las comunidades cuando se trata de realizar justicia. 
Si se parte de esto, se considera necesario mirar lo que hacen estas otras justicias, las cuales, en principio, no son comparables con la justicia estatal formal, particularmente, la indígena; pero, no se pueden negar los elementos que toma, asimila y modifica de la llamada administración formal de justicia en lo que a práctica u operación judicial se refiere. Por ello se hace una revisión en la práctica, para así establecer cómo una autoridad indígena, el Tribunal Superior Indígena del Tolima, así como los Jueces de Paz y Reconsideración ejercen la administración de justicia en una concepción que no es precisamente la formal-jurídica en toda su dimensión, que constituye un ejercicio democrático y novedoso de administración de justicia por operadores distintos al "juez formal" y al exacerbado formalismo jurídico, en el cual estas prácticas informales, culturales y sociales abren una compuerta de maneras no convencionales para abordar, tramitar y resolver conflictos de orden comunitario-comunal o social. De igual forma, se pretende identificar, a partir de las maneras de estos profanadores del Derecho, si efectivamente producen un campo o subcampo jurídico distinto al hegemónico del Derecho formal estatal.

\section{ADMINISTRAR JUSTICIA DESDE ABAJO}

El resguardo indígena de Togoima (Tierradentro, pueblo Nasa) y el Tribunal Superior Indígena del Tolima (TSIT) son parte de esta investigación, al igual que los Jueces de Paz y Reconsideración de algunas ciudades y pequeños municipios de Colombia. En otras palabras, las dos jurisdicciones especiales consagradas en la Constitución Política de 1991, en los artículos 246 y 247, respectivamente. Por otra parte, de la observación, revisión y estudio de estas experiencias de justicia se pueden reconocer unos elementos que permiten profundizar en la administración de justicia informal, sus alcances y sus propias limitaciones.

\section{La justicia en Togoima}

Tierradentro comprende los municipios de Páez e Inzá. El territorio del resguardo de Togoima se localiza en la jurisdicción del municipio de Páez, al nororiente del departamento del Cauca, ubicado sobre la margen derecha y al occidente del Río Páez. El resguardo de Togoima tiene una extensión aproximada de 2.822 hectáreas y una población cercana a los 3.500 habitantes. La lengua oficial en el territorio de origen es el nasa yuwe. "Derecho propio, interno o mayor o leyes internas: es lo mismo, no tiene diferencias entre sí, se refieren a las normas propias y de origen que los pueblos indígenas poseemos para mantener el control social" (Sisco, 2001, pp. 25-26).

En este sentido, para el resguardo de Togoima, el derecho mayor se concibe como los sistemas normativos propios de la comunidad, los procedimientos, la tradición oral, la memoria Ûus yakxnxi: es recrear la historia, escuchando las voces de los mayores y seguir sus huellas, la espontaneidad y sabiduría para actuar, según cada caso, y así comprender y valorar los elementos culturales, el estado material e inmaterial del ser humano y su armonía con sus semejantes y la naturaleza como expresión de integralidad del Nasa; todo esto constituye el trasfondo esencial del derecho mayor.

Derecho mayor también es la vivencia de mitos y ritos que son indispensables para la vida como pueblos. Por ello, se realizan varios rituales, a saber:

- Ritual del refrescamiento de varas para armonizar la autoridad y buscar que en la comunidad no se presenten problemas.

- Ritual de armonización del territorio, como la apagada del fogón para evitar la llegada de enfermedades o plagas a las personas, animales o plantas. 
- Ritual del cerco, para evitar la llegada de extraños que vengan con la intención de hacer daño al pueblo (por ejemplo los grupos armados que no respetan la autoridad de los cabildos).

- Ritual de ofrenda a los muertos, porque se cree que ellos siguen viviendo en otro espacio, y que igual necesitan alimento y bebida, para seguir acompañando y protegiendo a los que están en la tierra.

- Ritual del despertar de las semillas, para garantizar la subsistencia, con la calidad y diversidad de productos que un Nasa debe tener en su Tul o huerta familiar (Fxi'”' Zenxi'Sja'Dacxa Piyaaka, 2005).

\begin{abstract}
Todo este conjunto de rituales que revitalizan la vivencia como un pueblo de historia, constituye la base del derecho mayor que por generaciones se transmiten en procura de claridad y permanencia en el tiempo. Derecho mayor es todo el sistema jurídico milenario. Es lo legítimo toda vez que se fundamenta en leyes de los astros, $y$, del cosmos en general. Es mayor, pues viene desde que la tierra aún estaba en estado çëy. Ley de los máximos creadores de todo cuanto existe [...] uma y tay, (Tierra y sol) los truenos raíz original de la vida y toda expresión cósmica (Ramos, 2007).
\end{abstract}

\section{La Asamblea: máxima instancia de decisión}

La Asamblea en el resguardo de Togoima es el espacio de encuentro de todos los habitantes del territorio, de hombres y mujeres de todas las edades que atienden al llamado o a la convocatoria de la autoridad del cabildo. Se realiza en el lugar, fecha y hora indicados previamente. La convocatoria se hace a través de los llamados cabildantes menores, quienes recorren la totalidad del territorio para visitar a cada familia y entregarles el mensaje objeto de la convocatoria oralmente. Hoy en día, se cuenta con una emisora radial local comunitaria ubicada en la cabecera municipal
(Belalcázar), que facilita aún más la realización de estos eventos.

La asamblea es una instancia de información, deliberación, evaluación de acciones del cabildo, definición de políticas sociales y administrativas del territorio en su aspecto más integral posible, toma de decisiones trascendentales, planificación de la inversión de los recursos económicos propios y de los que se perciben del Estado; aprobación de resoluciones de carácter judicial o manejo y control territorial; construcción de estrategias para la convivencia armónica entre el Nasa y la naturaleza, y fijación de tareas y compromisos que debe adelantar el cabildo, es decir, la asamblea es un espacio participativo para legislar aspectos políticos, económicos y culturales.

Generalmente, este evento se desarrolla en la cabecera del resguardo, Togoima Centro, por ser un lugar tradicional donde se sabe que antiguamente lideraba al pueblo Togoimeño la Cacica Gullumus, personaje histórico de mucha importancia para el territorio. Sin embargo, la asamblea se puede realizar en otro lugar cuando la gente y el cabildo así lo considere pertinente, por ejemplo, si el comunero a quien se le va a aplicar el correctivo pertenece a determinada vereda o el hecho desarmonizante se cometió en esa vereda, a fin de que la aplicación del correctivo ayude a prevenir la comisión de futuros hechos similares y sirva para educar principalmente a esa comunidad, entonces se desarrolla en ese lugar.

De 3.500 habitantes aproximadamente asisten en promedio de 100 a 500 comuneros porque quienes asisten a la asamblea son los voceros de ideas pensadas desde otros escenarios de la comunitariedad expresados en reuniones familiares, reuniones de amigos, desde el fogón, los trabajaderos y la asamblea lo que hace es legitimarla, refrendar las diversas posiciones sobre un asunto, es la razón por el que el número de 
asistentes pasa a ser de segundo plano, sencillamente alguien pone la cara en la asamblea y expone (Ramos, 2007).

Durante el año se realizan cerca de cuatro asambleas ordinarias, previamente programadas por el cabildo al inicio del año, con temas específicos proyectados. El número de asambleas extraordinarias depende de las novedades que se presenten y se realizan, especialmente, para tratar temas de justicia.

Tres asuntos son los que se estudian en el presente artículo. El primero se refiere a la muerte de un miembro de la comunidad; el segundo es un hecho de violencia sexual y el tercero un atraco. Los tres hechos fueron conocidos y resueltos en la Asamblea de manera colectiva. Las características comunes son, entre otras, las siguientes:

- En cada caso la Asamblea conoce, delibera, realiza unas "pesquisas", confronta públicamente a los involucrados y resuelve aplicando el respectivo "correctivo", el cual, en la mayoría de estos hechos, es el cepo y el fuete.

- En todos los casos la comunidad interviene de manera indirecta, esto es, previamente comentando el asunto en múltiples lugares y se llega a una suerte de consenso y de manera directa en la Asamblea. Se puede desde interpelar directamente a los inculpados hasta la responsabilidad de toda la comunidad en lo acaecido.

- Los elementos culturales son tomados en cuenta y determinan la interpretación de los hechos.

- La espiritualidad se aplica para lo referente a los "correctivos". Es el elemento determinante para fijarlos y es la autoridad espiritual quien en últimas define el correctivo'.

1 Estas conclusiones preliminares son producto de primero, la observación y la participación en varias Asambleas del Resguardo; segundo, las entrevistas semi-estructuradas y a profundidad aplicadas, y tercero, las discusiones realizadas con las distintas autoridades del Resguardo.

\section{El Tribunal Superior Indígena del Tolima (TSIT)}

En el VI Congreso del Consejo Regional Indígena del Tolima (CRIT), realizado en Ibagué (Colombia) del 16 al 21 de diciembre del 2001, la Asamblea General de esta organización decidió crear el Tribunal Superior Indígena del Tolima (TSIT), con el objeto de fortalecer la administración de justicia en sus territorios y resolver múltiples inconvenientes que se presentaban dentro y entre cabildos; $y$ entre éstos y los funcionarios pertenecientes al sistema judicial nacional, es decir, los encargados de la administración de justicia estatal formal.

El Tribunal está compuesto por tres miembros principales y tres suplentes, que son líderes indígenas con suficiente experiencia e idoneidad organizativa, social y política. Según los Estatutos del CRIT, los seis miembros deben tener conocimientos sobre legislación indígena y jurisdicción especial indígena y no tener antecedentes penales, excepto por delitos culposos. Es elegido por el Congreso Regional Indígena para un periodo de cuatro años, con posibilidad de ser reelegidos por una sola vez. El ejercicio de la Justicia por parte del Tribunal Indígena inició con la denuncia de tres tipos de actores: el veedor(es) del CRIT, los miembros de base de las comunidades y la Justicia Ordinaria.

Gran parte de las denuncias recibidas por el Tribunal provienen del Veedor, quien lo hace a nombre propio, puesto que esto hace parte de sus acciones o como vocero de los miembros de las comunidades que quieren interponer denuncias en contra de los gobernadores o de otro tipo de autoridad que haya vulnerado derechos.

Desde el inicio de su funcionamiento, el TSIT ha trabajado coordinadamente con las autoridades judiciales de los municipios de Coyaima, Natagaima y Ortega principalmente, ya que son los municipios con mayor presencia indígena en el 
departamento del Tolima. En el caso de que los procesos se remitan por parte de juzgados y fiscalías municipales el trámite dado a este tipo de hechos es el siguiente:

- Recepción del expediente.

- Determinación de la pertenencia étnica de los involucrados.

- Notificación al gobernador indígena sobre los delitos de los que se le acusa, para que realice los respectivos descargos.

- Citar a una audiencia en la comunidad, en la que ocurrieron los hechos.

- En la audiencia se escuchan las partes, se observan las pruebas documentales -si las hay- $y$ dependiendo del caso, el TSIT toma la decisión inmediatamente o lo hace posteriormente.

EI TSIT ha sido muy cuidadoso en no asumir procesos que pueden ser solucionados en la comunidad. Por ello sólo admite quejas que no han podido ser tramitadas por alguna circunstancia, o hechos que involucran directamente a gobernadores indígenas. Cuando las denuncias corresponden a una verdadera segunda instancia, ya sea porque no hubo acuerdo en la comunidad, porque las partes quedaron inconformes con la decisión, o porque simplemente el Gobernador no quiso ejercer su función como autoridad judicial de la comunidad o porque el Gobernador solicitó el proceso a la justicia ordinaria y no hizo nada al respecto. En estas circunstancias el TSIT asume el caso.

De estos tipos de hechos comunitarios se revisan tres procesos ${ }^{2}$ adelantados por el TSIT, que permiten referir el papel del Tribunal para estas comunidades. Algunos de los elementos que se

2 Los tres conflictos son: no pago de la obligación alimentaria de un indígena de Natagaima; malos manejos de los recursos de la comunidad y un problema de linderos. pueden destacar a prima facie, sobre los tres procesos analizados son:

- La sensación de impunidad disminuyó entre los miembros de las comunidades pertenecientes al CRIT.

- Se fortaleció el ejercicio de la jurisdicción indígena por parte de todas las autoridades que tienen dicha responsabilidad.

- Las comunidades participan de diferentes maneras en todas las etapas adelantadas por el TSIT.

- Los fallos son emitidos en la mayoría de las oportunidades en presencia de la comunidad indígena.

\section{Los jueces de paz y reconsideración}

La Jurisdicción Especial de Paz es consagrada en la Constitución colombiana de 1991, en su Art. 247, el cual se encuentra ubicado en el título VIII o de la Rama Judicial, en el capítulo 5 o de las Jurisdicciones Especiales. El mencionado artículo señala: “La ley podrá crear jueces de paz encargados de resolver en equidad conflictos individuales y comunitarios. También podrá ordenar que se elijan por votación popular".

Su consagración fue el producto del consenso entre varias iniciativas de origen gubernamental y no gubernamental (Consejo Superior de la Judicatura \& Universidad de los Andes, 1999). Según estas propuestas, se buscaba crear una figura próxima a la comunidad, de origen popular, que resolviera conflictos que afectaran la convivencia cotidiana de una manera ágil y sin formalidades. Pero dicho proceso presentó dificultades en relación con la claridad de los conceptos de justicia comunitaria y el de jueces de paz, pues se carecía de información suficiente sobre éstos. Sin embargo, hubo un punto de encuentro conceptual en cuanto a la finalidad y la función de los jueces de paz, la cual se refiere -a grandes rasgos- a promover la convivencia comunitaria, colaborar en la solución y 
en la prevención de conflictos, y proferir sus fallos en equidad, eliminando los formalismos, a fin de facilitar el acceso a la justicia.

Posteriormente, se promulgó la Ley 497 de 1999, que regula la elección y la puesta en marcha de los jueces de paz en el país; por su parte, la motivación de esta ley puso de presente su papel de mecanismo de acceso a la justicia, pero, a su vez, la importancia en la formación de los jueces para el ejercicio responsable de la figura. En cuanto a la actuación de estos operadores informales de justicia, la Ley 497 en el artículo 22 señala:

\begin{abstract}
Procedimiento. El procedimiento para la solución de las controversias y conflictos que se sometan a la consideración de los jueces de paz constará de dos etapas que estarán sujetas a un mínimo de formalidades previstas en este título. Tales etapas serán una previa de conciliación o auto compositiva, y una posterior de sentencia o resolutiva.
\end{abstract}

Este artículo denota las etapas de la jurisdicción especial de paz, las cuales, básicamente, son dos y se denominan: una previa de conciliación o autocompositiva, sujeta a la voluntad de las partes y orientada por el juez de paz, y una posterior, de sentencia o resolutiva dirigida, proyectada y valorada exclusivamente por el juez de paz y eventualmente por el cuerpo colegiado de jueces, en el caso de solucionar la petición de reconsideración. En tal plano, la figura del juez de paz y de reconsideración acompaña, facilita y coadyuva la resolución de conflictos comunitarios o individuales que se pongan en su conocimiento.

En el presente trabajo se revisan varios conflictos en los que intervienen indistintamente jueces de paz y de reconsideración en varias municipalidades, para establecer cómo opera la solución del conflicto y su trámite por parte de este actor social. Los conflictos analizados ${ }^{3}$ son aquéllos que más comúnmente asumen estos jueces y tienen que ver esencialmente con la falta de vivienda (arrendamiento), falta de recursos para solventar los gastos básicos (deudas), cuestiones de la vida intrafamiliar y de la vida en común (lo público). De un conjunto de conflictos revisados (45 en total, de jueces de distintos municipios) se seleccionaron tres, que son referentes en cada tipo de conflicto y reúnen los elementos mínimos para adelantar el análisis.

Algunos de los elementos encontrados en los conflictos en los que intervienen estos actores son:

- El discurso de la ley: constituye un marco que se ha impuesto como referente para definir los asuntos por resolver, por parte de los jueces de paz.

- La actuación de los jueces de paz: afianza el campo jurídico formal, no obstante, las maneras de usar la ley recrean un subcampo jurídico, en el cual estos profanadores del Derecho establecen un campo de dominio social de los conflictos.

- Las maneras más comunes de profanación del Derecho ocurren en el uso creativo de la ley: la ley sirve para todo, la ley es el acuerdo de las partes, la ley no aplica para casos concretos, la ley es insuficiente y no existe ley que se ocupe de la comunidad.

- La resolución de conflictos, ya sea en escenarios urbanos o rurales, parte de un proceso constructivo sobre el objeto del conflicto y su decisión; de esta solución participan los interesados, las autoridades comunales, dirigentes o representantes de la comunidad de diferentes niveles orgánicos de éstas o miembros de la comunidad, vecinos y familiares. Lo importante en estas reuniones (audiencias) es que todos

3 Se revisaron 45 fallos en equidad de jueces de paz de diferentes municipios y ciudades de Colombia, entre ellos: Cali, Medellín, Ibagué, Dos Quebradas, Buga, Florida y Bogotá. 
Ios actores pueden deliberar y participar para generar acuerdos.

- No obstante, los jueces de paz y de reconsideración no privilegian el arreglo colectivo de las diferencias, hostilidades 0 antagonismos vecinales y comunitarios. Incluso, los asuntos que por su naturaleza se deberían resolver en el foro pocas veces se hace de manera pública o colectiva.

- La práctica desarrollada por los jueces urbanos en los años transcurridos demuestra que se privilegia principalmente el arreglo particular de todos los asuntos. Esto ocurre gracias a que los hechos conocidos por estos jueces se ubican en la frontera de lo formal-informal, pero que mayoritariamente son asuntos de carácter jurídico y pocos conflictos sociales son resueltos por estos actores de la justicia.

\section{¿DERECHO?}

En este punto cabe preguntarse si todo lo anteriormente expuesto es Derecho. Un problema constante en este campo de conocimiento es que no hay consenso sobre la naturaleza sociojurídica de los hechos (éstos y otros) que son objeto de análisis. Sin embargo, en el reclamo de la aceptación de sistemas no oficiales de normas jurídicas hace falta una definición:

\begin{abstract}
Griffiths y Woodman ven la dificultad en que no se puede detectar empíricamente el deslinde entre normas jurídicas y sociales como la moral, la buena conducta, etc. En consecuencia, la mayoría de autores tienen un concepto bastante amplio. Woodman propone por ejemplo, entender como "derecho" un "continuo" que rige desde normas legales claras -como el derecho estatal- hasta formas más vagas como el control social informal (Brandt, \& Franco Valdivia, 2006).
\end{abstract}

Para Bohannan (1989, pp. 43-58), el Derecho es distinto de la costumbre, pues mientras ésta es un cuerpo de normas que la gente generalmente obedece, el Derecho se caracteriza porque la gente lo recrea en contextos específicos. El Derecho también es costumbre, pero un tipo de costumbre que ha pasado por un proceso de reinstitucionalización, es decir, que ha sido reafirmada dentro del campo de las instituciones legales.

En el libro critica las posturas que sostienen que la costumbre mantiene el orden social o que restringe la existencia del Derecho a unas cuantas sociedades. A pesar de que Pospísil comparte con otros antropólogos la idea de que el Derecho es un tipo de control social, su crítica se dirige hacia aquéllos que consideran sólo uno o dos elementos para definir el Derecho. Clasifica estos académicos en tres categorías: aquéllos que ven el Derecho como normas abstractas; aquéllos que lo conciben dentro de patrones de comportamiento real y finalmente, aquéllos que lo encuentran en principios derivados de decisiones legales.

La existencia de sociedades que carecen de códigos escritos o de hombres sabios que recuerden las normas, cuestiona la postura que sostiene que el Derecho es un conjunto de normas abstractas. Es más -según Pospísil- las normas abstractas no siempre son operacionales en términos de control social, porque la mayor parte del tiempo estas sociedades tienen lo que él llama normas muertas o carentes de una función controladora. Por otra parte, enfatiza que no todo el comportamiento social constituye Derecho; en efecto, los individuos usualmente actúan de acuerdo con costumbres prohibidas por sus Estados y son castigados, por ello el comportamiento humano no podría ser entendido como Derecho.

En cuanto a la tercera postura, el autor asevera que el Derecho debe ser deducido de las decisiones y no al contrario, porque las normas del deber ser siempre son diferentes de los principios impuestos mediante decisiones judiciales. Antes que un énfasis en las reglas abstractas o en las resoluciones 
judiciales, Pospísil propone que para definir el Derecho se consideren ambas.

La imposibilidad de acceder al Derecho -si se considera como objeto de estudio indistintamente las normas abstractas o la práctica social o las decisiones de los jueces- Ileva a Pospísil a postular un método de análisis del Derecho, basado en las decisiones de los operadores de éste. Al verificar el Derecho en las decisiones judiciales, esta aproximación clarifica las ambigüedades de normas abstractas, que forman parte de la estructura social. Evidentemente, Pospísil buscaba una categoría de Derecho que no colisionara con el concepto antropológico de estructura social.

Por otra parte, existe una idea clara de los modos clásicos de producción del Derecho -por lo menos desde el positivismo jurídico-, sin embargo, falta dilucidar desde cuáles otros lugares se produce regulación y su incidencia en el gran campo jurídico. La más relevante -en mi opinión- es la que denomino el manierismo ${ }^{4}$; es decir, por un lado, la forma propia de entender y de aplicar el Derecho en cada contexto socio cultural y, por otro, las maneras de realización social de lo justo. Este manierismo -y sus maneras- no son siempre "prácticas jurídicas propiamente dichas", pues se autoconstituyen en una categoría no propiamente jurídica.

Las comunidades adaptan el Derecho a su acomodo y de múltiples formas establecen usos sociales de éste, coloquialmente a su manera lo entienden y lo aplican. La preocupación de los ciudadanos y ciudadanas no es el Derecho en sí mismo, para ellos es mucho más significativa la justicia. La materialización de la justicia es lo que

$4 \quad$ El manierismo en su acepción original es un estilo artístico del siglo XVI, caracterizado por la expresividad y la artificiosidad. Es precisamente en ese sentido que quiero usar dicha palabra para significar cómo las comunidades ingeniosa y artificiosamente usan el Derecho. se comprende como justo, ya que el derecho usualmente es injusto, puesto que así lo entiende cualquier persona.

Esto lleva a no ignorar el universo social del que emerge el derecho y de ahí la pregunta que nos formula Pierre Bourdieu: "¿Cuál es el universo social concreto en el cual se produce y se ejerce el Derecho? Entre los teóricos del Derecho existen quienes lo quieren librar del peso de lo social, pues tener una "ciencia jurídica" implica estar ausente de los hechos perturbadores de la producción del conocimiento objetivo.

No obstante, algunos juristas consideran que el Derecho protege a los individuos y a los diferentes grupos e intereses sociales; es decir, lo consideran como la dimensión social o emancipatoria del derecho, apreciación que se considera bastante reduccionista, puesto que la práctica social de las relaciones entre individuos y grupos sociales no se encuentra determinada siempre por normas jurídicas.

El Derecho no nace solamente de las normas, sino que también emerge de los operadores e interpretes fundamentalmente, pero cada comunidad libremente lo determina o modifica. A pesar de la eficacia simbólica del Derecho y de sus nombradores, existen grietas del sistema jurídico que no son cubiertas por ningún tipo de parche que evite la entrada de los virus sociales que se suscitan por la no realización de lo justo; los detentadores del aparato jurídico no resuelven las necesidades sociales, sólo mantienen el statu quo.

\section{TRES JUSTICIAS Y UN SOLO DERECHO VERDADERO}

Son tres las categorías que se pretenden poner en cuestión: la llamada justicia comunitaria, la justicia indígena y la denominada justicia informal; 
todas miradas en el campo de la práctica social ${ }^{5} y$ judicial. El asunto no se circunscribe a que a mayor presencia de comunidad más justicia comunitaria, o a menor presencia de ella, se defina como justicia estatal informal. El asunto no es meramente semántico, sin dejar de reconocer que hay una falta de claridad frente a las distintas categorías que se asumen por los diferentes académicos.

El sesgo político y la falta de claridad conceptual son el sustrato de esta discusión. Necesariamente se requiere develar qué tanto las concepciones de estas prácticas de justicia son eminentemente una perspectiva no diferenciada del ejercicio de dominación del derecho estatal. Por ello, resulta imprescindible iniciar por aclarar aquello que se entiende por justicia comunitaria, lo que se denomina justicia indígena y lo que se entiende por justicia informal; todo ello en el entendido de tres concepciones de justicia que son correlato de una confusión conceptual que se puede empezar a aclarar.

\section{Justicia comunitaria}

De las definiciones que se plantean (tabla 1) se destacan tres aspectos: en primer término, la especificidad de llamarlas prácticas, con la intención de volver a revisar de fondo lo que implica una práctica; segundo, lo que se reconoce como procedimientos y mecanismos, como los criterios de justicia de la comunidad, y tercero, la relación espacio-escenario y actores.

Usualmente, más que Derecho estatal, la justicia comunitaria aplica preceptos locales, así como formas de razonamiento de sentido común. EI atuendo, las formas de actuar, el lugar físico y los

5 Por práctica social se entiende un complejo de acciones humanas que realizan los miembros de un cierto grupo social, orientados por representaciones, que pueden ir desde creencias y modelos hasta complejas teorías científicas y que tienen una estructura axiológica, es decir, normativo-valorativa. modos de expresión son similares a los empleados por la comunidad cercana. El elemento cultural subyace igual en casi todos los planteamientos. Diferentes intelectuales de varias ONG en 2003 se dieron a la tarea de profundizar el tema de la justicia comunitaria, discusión que se recogió en anotaciones y glosas sobre un debate necesario sobre la justicia comunitaria, en el que se señala que ésta y sus prácticas se estructuran y singularizan en torno a los siguientes elementos mínimos (Instituto Popular de Capacitación, 2003):

- Una lógica acerca de lo comunitario, que bajo situaciones específicas, constriñe y se impone sobre algunas disidencias individuales.

- Un acervo de tradiciones y de costumbres, del cual los sujetos derivan un margen de certeza y de predecibilidad, al igual que cierta eficacia simbólica.

- Una regulación de las relaciones de poder, bajo concepciones que fácilmente pueden resultar "no democráticas".

- Una margen de discrecionalidad y de autonomía, en la cual los sujetos pueden, por ejemplo, distanciarse de los dictámenes de la cultura, enfrentar creativamente algunas situaciones nuevas no prescritas por la costumbre, es decir, las prácticas de justicia comunitaria producen pensamiento, entre otras cosas.

- Una elaboración narrativa de sus propias prácticas que varía en grados de complejidad y de explicitación.

El punto relacionado con prácticas no democráticas es de los más llamativos, por el carácter de antidemocráticas que pueden llegar a ser estas prácticas de justicia. La mayoría de intelectuales del tema hacen alusión a esta hipótesis, sin estar probada a la fecha por un trabajo empírico que lo corrobore. 
Tabla 1. Conceptos clásicos de Justicia Comunitaria

\begin{tabular}{|c|c|c|}
\hline Rosembert Ariza S. & $\begin{array}{l}\text { Ministerio del Interior y de } \\
\text { Justicia (Colombia) }\end{array}$ & Sally Engle Merry \\
\hline $\begin{array}{l}\text { La Justicia Comunitaria es } \\
\text { el conjunto de prácticas que } \\
\text { regulan y autorregulan } \\
\text { las relaciones sociales, mientras } \\
\text { éstas sean desarrolladas } \\
\text { en las comunidades. Se expresa } \\
\text { en los procedimientos y en } \\
\text { los mecanismos que recogen } \\
\text { el sistema de valores y } \\
\text { creencias y de tradiciones } \\
\text { y costumbres que realizan } \\
\text { los criterios de justicia de la } \\
\text { comunidad. Una característica } \\
\text { muy importante de esta justicia } \\
\text { es que logra relacionar el } \\
\text { espacio, el escenario y los } \\
\text { actores en conflicto. Es justicia } \\
\text { comunitaria por el actor que la } \\
\text { desarrolla y por la capacidad de } \\
\text { gestión en la resolución de los } \\
\text { conflictos en su propio entorno. }\end{array}$ & $\begin{array}{l}\text { Entiende por justicia } \\
\text { comunitaria todas aquellas } \\
\text { expresiones e instituciones } \\
\text { que hacen parte de la visión } \\
\text { del mundo jurídico que una } \\
\text { sociedad construye y legitima. } \\
\text { Este conjunto de instituciones } \\
\text { reconoce procedimientos, } \\
\text { normas, operadores comunes } \\
\text { que hacen de dicha justicia una } \\
\text { posibilidad comunitaria para } \\
\text { la solución de los conflictos } \\
\text { (Documento interno Dirección } \\
\text { de Acceso a la Justicia). }\end{array}$ & $\begin{array}{l}\text { Considera que la justicia } \\
\text { comunitaria "es un proceso } \\
\text { relativamente informal en } \\
\text { cuanto al ritual [...] utilizado, } \\
\text { no profesional en el lenguaje } \\
\text { y personal empleados, locales } \\
\text { en el alcance y limitado en } \\
\text { la jurisdicción, para adoptar } \\
\text { decisiones y hacer obligatorio } \\
\text { el cumplimiento de una serie } \\
\text { de normas" (Merry, 2003, p. 41) } \\
\text { o acuerdos. }\end{array}$ \\
\hline Rodrigo Uprimny Yepes & $\begin{array}{l}\text { ATI (Asociación de Trabajo } \\
\text { Interdisciplinario) }\end{array}$ & $\begin{array}{l}\text { (Santos, 1995a; Merry y } \\
\text { Milner, 1993: 3-30) }\end{array}$ \\
\hline $\begin{array}{l}\text { "[...] la justicia comunitaria y } \\
\text { la justicia alternativa son } \\
\text { prácticas de control social, y ante } \\
\text { todo de resolución de conflictos, } \\
\text { que tienen lugar dentro de } \\
\text { determinadas comunidades y } \\
\text { que se caracterizan } \\
\text { por pretender suministrar } \\
\text { pacíficamente justicia a través } \\
\text { de vías diferentes o alternas a } \\
\text { aquellas ofrecidas por el aparato } \\
\text { estatal” (Uprimny Yepes, abril de } \\
\text { 2005, p. 34). }\end{array}$ & $\begin{array}{l}\text { La justicia comunitaria tiene } \\
\text { como actor principal a la } \\
\text { comunidad y en esa medida } \\
\text { se expresa a través de } \\
\text { necesidades, valores e intereses } \\
\text { compartidos, contextualizados } \\
\text { en un espacio sociogeográfico } \\
\text { particular (De Sousa Santos \& } \\
\text { García Villegas, 2001). }\end{array}$ & $\begin{array}{l}\text { Se entiende por Justicia } \\
\text { Comunitaria el sistema } \\
\text { de normas fundamentalmente } \\
\text { consensual opuesto a las reglas } \\
\text { estatales, de acuerdo con el } \\
\text { cual los conflictos se resuelven } \\
\text { de manera autocompositiva } \\
\text { y que expresa la existencia } \\
\text { de una comunidad autónoma } \\
\text { frente al Estado. }\end{array}$ \\
\hline
\end{tabular}


Inicialmente, de estos planteamientos se puede dejar una reflexión significativa sobre el carácter y el alcance político de la justicia comunitaria, en un contexto de guerra interna, como es el caso colombiano, marcado por dinámicas económicas y sociales abiertamente excluyentes. Entonces, ia qué se refiere, en últimas, la llamada justicia comunitaria?

\section{Justicias indígenas}

[...] Hoy nos convoca la urgencia de hacer conocer al mundo cuál es nuestra concepción de la justicia, por cierto incomprendida por el mundo occidental. Concepción incomprendida por sus diferencias, rechazada y tildada de inhumana por la ignorancia. Tenemos tanto que decir, que las palabras razonadas con juicio llenarán el espacio en el que anida la discriminación. Que la reflexión sea juez inexorable de la justicia de nuestras palabras

(Piñacué, 1997, p. 32)

Cuando el antropólogo jurídico Herynaldi Gómez $(2006$, p. 3) se refiere al derecho indígena, lo reconoce como una categoría que involucra tanto el derecho "propio o interno" como el derecho nacional. De la acepción en plural de "justicias indígenas" es de resaltar, por un lado, que no existe una "justicia indígena", en general, sino una diversidad de concepciones, de prácticas de justicia y de nociones de lo injusto y lo justo en cada uno de los diferentes pueblos indígenas, es decir, no existe una justicia o conjunto de normas, procedimientos, usos y costumbres básicos o afines, que agrupen o con las que se identifiquen los 86 pueblos indígenas de Colombia. Por otro lado, las concepciones, normas, procedimientos, usos y costumbres de la justicia no son homogéneos en un mismo pueblo indígena (en especial, en los andinos del sudoeste colombiano conformados territorialmente por resguardos y cabildos). En suma, se debe resaltar el carácter diverso de las justicias indígenas y para señalar la diversificación intraétnica de prácticas de justicia. Diversidad o diversificación que, entre otros factores, han dependido:
- De la relación y la combinación de procesos y aspectos tan variados como el espacio cultural en o por los cuales se origina, transita y resuelve el conflicto, redes de parentesco, chamanismo y cabildo, por ejemplo.

- De la experiencia y tipo de relación histórico cultural de cada cabildo con el derecho estatal y la sociedad nacional.

- Del grado de vigencia de la tradición y transformación o dinámica de sus concepciones y prácticas.

- De los tipos de apropiación y uso de normas jurídicas exógenas.

- De la fortaleza de la organización comunitaria interna y ejercicio de la autonomía étnica de cada cabildo.

- De la legitimidad o reconocimiento del que gozan o adolecen los diferentes tipos de autoridad existentes y del tipo o "naturaleza" de la trasgresión por resarcir o del conflicto por resolver (Gómez Valencia, octubre de 2006, p. 3).

Por otro lado, Hans Jurgen Brandt y Rocío Franco V. otorgan al término "derecho consuetudinario" el sig nificado más amplio posible, haciendo referencia

\section{[...] al sistema de normas, principios, valores, prácticas, instituciones, usos y costumbres considerados legítimos y obligatorios para los grupos sociales investigados y que les permite regular su vida social, organizar el orden público interno, establecer derechos y deberes, resolver conflictos y tomar decisiones (Brant \& Franco Valdivia, 2006, p. 13).}

De acuerdo con Rodolfo Stavenhagen, el concepto de derecho consuetudinario "[...] se refiere a un conjunto de normas legales de tipo tradicional, no escritas ni codiicadas, distinto del derecho vigente en un país determinado" (1991, p. 304). A pesar de las objeciones que se le puedan hacer a estas denominaciones, lo que importa es comprender 
que hacen parte, en el presente, de su deliberado propósito de afirmación de su diferencia cultural y de su "autonomía política" para ejercerlo de manera "propia" y de una estrategia de posicionamiento político ante el mundo "externo" desde una perspectiva "interna".

En Colombia, a partir de la jurisprudencia, se afirma que la aplicación de la jurisdicción indígena no depende de la regulación legal que de ella se haga, sino del ejercicio mismo de dicha justicia en cada comunidad. Es decir, que desde el momento en que se aprobó definitivamente la Constitución Política de 1991, la justicia indígena es reconocida legalmente por el Estado colombiano y su desarrollo concreto ha dependido de cada pueblo indígena, de los 86 existentes.

Como indica Raquel Yrigoyen (1999, p. 31):

La categoría "derecho indígena" no excluye la co-existencia de diversos sistemas regulatorios que se intersectan $\mathrm{y}$, eventual mente, se disputan regular el mismo aspecto de la vida social; se trata de grados. Probablemente, hay un mayor grado de regulación de la vida social por el derecho indígena cuando los niveles de cohesión social sean más altos, asimismo, puede haber más distancia geográfica con respecto a los centros urbanos y que la violencia política haya tenido menor efecto $y$, en consecuencia, haya menor presencia de sistemas que también buscan regular la vida social (sectas, presencia estatal, etc.).

En otras palabras, la justicia indígena se la puede definir como el conjunto de reglas que establecen la configuración de las formas de gobierno, la creación, la organización y las atribuciones de competencias de los órganos de autogobierno, que garantiza a los pueblos indígenas el pleno acceso de sus derechos fundamentales, los cuales son reconocidos en diversos instrumentos jurídicos, así como el conjunto de pautas de conducta colectiva en que se basan estos pueblos para la administración de justicia en sus comunidades.

\section{La justicia informal}

Se va a adoptar la definición de Raquel Yrigoyen F. (2000, p. 202), que la entiende como el sistema informal de justicia, es decir, una institución con la autoridad reconocida para administrar justicia, que posee normas y los medios para crearlas o cambiarlas, autoridades y los medios para escogerlas, procedimientos para arreglar disputas, sanciones y sistemas para reforzarlos.

Los llamados sistemas legales informales parecen mayormente complementar o sustituir la ley del Estado. De hecho, una de las motivaciones de los constitucionalistas -los que formalmente reconocieron la ley indígena y campesina en Colombia, Bolivia y Perú- era compensar las deficiencias de la policía y cortes, esto implica extender la eficiencia, la autoridad y la legitimidad de la ley indígena y campesina en áreas sin ley y a las cuales el Estado no podía llegar. La informalidad de estos sistemas es lo que constituye su autonomía y genera su autoridad. Estos dos aspectos producen los espacios de empoderamiento ciudadano de construcción social de la justicia.

Donna Lee Van Cott (2003) estableció el siguiente planteamiento para entender los sistemas informales de justicia; afirmó que no se deben ver "complementarios" ni "sustitutivos", como dos categorías separadas. Su estudio de los sistemas de justicia comunitaria informal sugiere que estas categorías se ven mejor como dos polos de un continuum. Por una parte, en el extremo "sustitutivo", las comunidades indígenas y campesinas están geográficamente distantes de las instituciones formales y son responsables de la administración de justicia y de la resolución de disputas. Por otra, en el extremo "complementario", las comunidades indígenas y campesinas trabajan de cerca con la policía y las cortes para dividirse estas responsabilidades. En el medio hay más casos de instituciones informales de justicia, que coordinan su trabajo 
con los funcionarios estatales en la medida en que sea necesario, dada la presencia de presión interna o externa y la disponibilidad de tales servicios.

Julio Faundez (2003), en las conclusiones de la primera parte de su estudio, sostiene que el papel del Estado frente a los Sistemas Informales de Justicia toma muchas formas; en el caso de los jueces de paz, las comunidades nativas y campesinas se expresa en un laberinto de regulaciones y en la pretensión de cooptación, por parte de diferentes actores institucionales. Igualmente, los actores sociales pretenden el reconocimiento legal e institucional, con el objeto de que sus actuaciones se reconozcan y tengan validez frente al sistema legal formal.

La interacción de los Sistemas Informales de Justicia con las instituciones estatales tiene diferentes implicaciones; en el caso de Perú las rondas campesinas tienen un alto perfil político gracias al interés de los gobiernos de usarlos y manipularlos. No ocurre lo mismo con las comunidades indígenas, en las que se puede ver claramente una continuación histórica de modelos de discriminación contra las personas indígenas. Faundez agrega que esto ocurre cuando los Estados son demasiado débiles para proporcionar justicia, ya que los sistemas informales formalmente reconocidos y semi-autónomos pueden complementar los esfuerzos del Estado y así mejorar la calidad de la ciudadanía. Aunque el reconocimiento formal parece necesario para evitar conflictos jurisdiccionales, también parece necesario que los sistemas no estatales retengan buena parte de su "informalidad".

Algunos van mucho más allá, argumentando que los sistemas y las normas informales tienen -o tendrán, si se les da el reconocimiento apropiado- un efecto positivo en la ley del Estado. Sin embargo, conectar los sistemas de justicia informal y formal ha provocado un debate intercultural constructivo sobre los defectos de ambos sistemas, y su creciente y mutua responsabilidad.
Más leña al tercio

En los últimos años en Colombia se constituyó y se proclamó la justicia en equidad, como un subcampo de la llamada justicia comunitaria, para unos, y como un programa de acceso a la justicia, para otros. Esta mirada administradora encuentra su culmen en esta categoría, pues reúne a los conciliadores en equidad y a los jueces de paz como falladores en equidad bajo una misma acepción; asimismo, determina a estos sujetos como "operadores" de justicia o autoridades locales de justicia (nomenclatura alterna para otros). Esta denominación, puede pasar como simple capricho intelectual, sino fuera por el alcance que ésta tiene en el plano institucional y jurídico del país y los alcances que se están develando en las prácticas locales de justicia.

Es el caso de la jurisprudencia sobre equidad del magistrado Manuel José Cepeda ${ }^{6}$, a propósito del arbitramento en equidad, éste lo relaciona con la justicia en equidad y con los Mecanismos Alternativos de Solución de Conflictos (MASC), dejando entrever un límite legal bastante definido a esta justicia de tipo institucional.

Otros académicos proponen una tendencia que empieza a ser predominante en el país, la cual se refiere a la solución de conflictos de grupos étnicos, énfasis mediado más por recursos de cooperación internacional, que por estudios profundos en el tema. Dicho enfoque pretende mantener el debate en el mundo cultural, pero circunscrito a facultades de jurisprudencia y a centros de conciliación jurídicos. Las agendas de las agencias de cooperación y de las propias agencias gubernamentales señalan un camino que preten-

6 Corte Constitucional. Sentencia SU-837 de 2002, M.P. Manuel José Cepeda Espinosa. En igual sentido ver la Sentencia C-1547 de 2000, M.P. (E) Cristina Pardo Schlesinger, Demanda de inconstitucionalidad contra el artículo 38 numeral $1^{\circ}$ del Código de Procedimiento Civil. 
de organizar desde la visión de estos actores del campo del sistema informal de justicia.

Evidentemente, lo anterior consiste en recargar el campo informal con categorías vacías de sentido; esto ocurre por lo que ya se había señalado con respecto a la agenda de cooperación. Esta intervención internacional reorganiza el campo en categorías que se ajustan a los mandatos del mercado internacional, a las tendencias desregualdoras y a las desjudicializantes, lo que lleva a generar categorías como la justicia en equidad, que concuerdan con su política de cooperación al desarrollo. Estas agencias han distribuido el campo en justicias étnicas (indígenas, afrodescendientes, rom y raizales), justicia en equidad (conciliadores en equidad y jueces de paz), además de los propios MASC (conciliación en derecho, arbitramento, centros de conciliación, unidades de mediación y conciliación, etc.), la Ilamada justicia administrativa, y un último grupo lo constituye la justicia que garantiza las políticas de acceso, entre ellos, programas como las Casas de Justicia, Consultorios jurídicos y otros tipos de servicios legales. Todo esto, sin duda, es más leña para esta hoguera de confusiones.

\section{CAMPOS DE LAS NUEVAS FORMAS DE DOMINACIÓN JURÍDICA}

\section{Algunas conclusiones preliminares}

Más allá del progresivo debate de la Teoría Crítica del Derecho, del Estado y de la democracia, los procesos de reformas a la administración de justicia que vienen ocurriendo en los últimos años en América Latina han impactado y acotado de diferente manera la dimensión de las llamadas justicias.

En el contexto regional, los procesos que dan paso a estas justicias, si bien se originan desde un fundamento y una óptica común, han seguido cursos de acción diferentes. En algunos países han estado más centrados en la estructura institucional del Estado; en otros, más abiertos a la comunidad, en algunos se han instalado en una pequeña apertura de la propia función judicial y en otros directamente se han generado a partir de la creación y la regulación de figuras expresas que instituyen la función de justicia informal.

Parte de estos procesos se vieron complementados en la década del noventa por reformas de orden constitucional, que si bien tuvieron a la vista una tarea de descongestión judicial, consagraron figuras que favorecen el desarrollo de una justicia indígena, comunitaria e informal, al promover modalidades, como la mediación, la conciliación, el arbitraje, la justicia indígena y la justicia de paz. Así ha ocurrido principalmente en el marco constitucional de Perú, Ecuador, Venezuela y Colombia y también en el caso boliviano, donde se faculta a las autoridades indígenas y campesinas para solucionar conflictos de conformidad a sus costumbres y procedimientos.

El tratamiento de estas justicias, tanto en su concepción teórica y de sus prácticas comunitarias, como de las figuras institucionales para su aplicación, en las cuales más se ha experimentado un desarrollo en el continente, sin duda, es Colombia. El escenario nacional es referencia central, ya que se esmera en tener una mayor regulación institucional desde el Estado, a través de su Constitución Política, leyes especiales, decretos y dependencias ministeriales y gubernamentales específicas abocadas a esta función. Su posición privilegiada se ve también en la proliferación sorprendente de varios espacios desde la sociedad civil y de las prácticas cotidianas comunitarias que han abordado y desarrollado crecientemente el tema de la justicia.

De estas prácticas de justicia, que constituyen sin duda el campo de la justicia informal, se encuentra que comparten varios presupuestos comunes: 
- La especificidad y vigencia de unas prácticas sociales y culturales de justicia indígena y comunitaria, tanto en concepción, principios y práctica, con respecto al sistema jurídico estatal y, por lo tanto, la dificultad de su comparación.

- La importancia de la instancia familiar y comunitaria (asamblea) en el ejercicio de la justicia, como espacios privilegiados de resolución de conflictos y reconstitución del tejido social.

- La permanencia de una estructura de poder tradicional en la práctica de la justicia y elección de autoridades, junto con la incorporación de nuevos elementos, mostrando de esta manera la condición flexible y dinámica de las culturas locales ante los cambios.

- Estas justicias son visibles gracias al reconocimiento legal y muchos de los mecanismos e instrumentos informales de resolución de

\section{BIBLIOGRAFÍA}

Álvarez, Gladys Stella y Highton, Elena Inés. (Junio de 2001) La mediación en el panorama Latinoamericano. Sistemas Judiciales, Año 1 (1).

Asociación de Cabildos de Tierra Dentro Nasa Cxhacxha y Juan Tama. (2005) Desde la diversidad tejiendo vida. Los tejidos Nasa, Cosmovisión y simbología. Popayán: Consejo de Familia Programa Mujer.

Assier-Andrieu, Louis. (1996) Le droit dans les societes humaines. París: Editions Nathan.

Borrero García, Camilo (compilador). (2003) Justicia alternativa -Estudios de caso. Bogotá: Centro de Investigación y Educación Popular -CINEP y GTZ.

Bohannan, Paul. (1989) Justice and Judgment among the Tiv. Illinois: Waveland Press.

Bohannan, Paul (editor). (1967) The Differing Realms of the Law. In Law and Warfare. Studies in conflictos nacen al amparo del Estado o piden su reconocimiento.

Las características anteriores permiten concluir que estas prácticas configuran un derecho social real, de la vida cotidiana, pues los operadores que las desarrollan son hombres y mujeres de carne y hueso, que comprenden las necesidades de los llamados "usuarios" de la justicia y entienden, esencialmente, que éstos son personas. Asimismo, se juegan en los conflictos que conocen las emociones, los afectos, un lugar en las relaciones interpersonales, sus intereses, pero, sobre todo, se juegan el poder, que configura ser actores de un campo privilegiado a los profesionales y a los nombradores oficiales de las fórmulas sacras del orden social. Ellos (los profanos), a su manera, resuelven cómo vivir, sin tener que derrotar al otro.

the Antropology of Conflict. New York: The Natural History Press.

Consejo Superior de la Judicatura y Universidad de los Andes -Centro de Investigaciones Sociojurídicas. (1999) Bases para la organización de Jueces de Paz en Colombia. Imprenta Nacional de Colombia.

De la Torre Rangel, Jesús Antonio. (2004) El derecho que nace del pueblo. Bogotá: Fundación para la Investigación y la Cultura.

De Sousa Santos, Boaventura y García Villegas, Mauricio (editores). (2001) El caleidoscopio de las justicias en Colombia: análisis socio-jurídico (tomos I y II). Bogotá: Siglo del Hombre Editores, Uniandes, Colciencias y Universidad Nacional de Colombia.

De Sousa Santos, Boaventura y García Villegas, Mauricio. (1991) Estado, Derecho y luchas sociales. 
Bogotá: Instituto Latinoamericano de Servicios Legales Alternativos -ILSA.

Corporación Gestión y Desarrollo Ciudadano. (2005) Ejercicio del Derecho Propio - El caso del Tribunal Superior Indígena del Tolima -CRIT. Ibagué: Agencia los Estados Unidos para el Desarrollo Internacional (USAID), Checchi and Company Consulting Colombia y Gobernación del Tolima.

Faundez, Julio. (2003) Non-State justice systems in Latin America, Case Studies: Peru and Colombia. Paper prepared for the DFID Workshop on "Working with Non-State Justice systems", 6 y 7 de March, 2003.

Faundez, Julio. (2006) Should Justice Reform Projects Take Non-State Justice Systems Seriously? Perspectives from Latin America. University of Warwick.

Gómez Valencia, Herinaldy. (2000) De la justicia y el poder indígena. Popayán: Editorial Universidad del Cauca.

Gómez Valencia, Herinaldy. (Octubre de 2006) Justicias orales indígenas y sus tensiones con la ley escrita. Ponencia presentada en el V Congreso de la Red Latinoamericana de Antropología Jurídica (RELAJU), Oaxtepec, Morelos (México), Octubre 16 a 20 de 2006.

Heller, Agnes. (1987) Sociología de la vida cotidiana. Barcelona: Editorial Península.

Instituto Latinoamericano de Servicios Legales Alternativos (ILSA) y Red de Justicia Comunitaria (editores). (2003) El Otro de Derecho No. 30, Variaciones sobre la justicia comunitaria. Bogotá: Instituto Latinoamericano de Servicios Legales Alternativos (ILSA) y Red de Justicia Comunitaria.

Instituto Popular de Capacitación. (2003) Contrastes sobre lo justo: debates en justicia comunitaria. Medellín: Instituto Popular de Capacitación (IPC).
Merry, Sally Engle. (2003) Una clasificación de la justicia popular. El Otro Derecho, No. 30, Variaciones sobre la Justicia Comunitaria. Bogotá: Instituto Latinoamericano de Servicios Legales Alternativos (ILSA) y Red de Justicia Comunitaria

Perafan Simmonds, Carlos César, et al. (1997). Sistemas jurídicos Tukano, Embera, Sikuani y Guambiano. Bogotá: Instituto Colombiano de Cultura.

Piñacue, Jesus Enrique. (1997) Aplicación autonómica de la justicia en comunidades paeces. Una aproximación. En Del olvido surgimos para traer nuevas esperanzas. La Jurisdicción Especial Indígena. Bogotá: Ministerio del Interior.

Plan de Vida de la Asociación de Cabildos Juan Tama. (2005) Pensamiento ancestral: por la construcción del tejido social y el fortalecimiento de las relaciones interculturales.

Pospísil, Leopold. (1974) La antropología del derecho. Una teoría comparativa. New Have: HRFA.

Pospísil, Leopold. (1996) The attributes of law. In P. Bohannan (editor). Law and Warfare. Studies in the anthropology of conflict. New York, The Natural History Press.

Ruiz Sánchez, Carlos Ariel. (2000) Donde estemos estamos con el pensamiento propio: Elementos de Jurisdicción Especial Indígena y prácticas comunitarias de justicia. Popayán: FUNCOP (Cauca), RJCTC y AESCO.

Sanchez Botero, Esther. (2000) The Tutela-System as a Means of Transforming the Relations between the State and the indigenous Peoples of Colombia. En Willem Assies et al. (eds.). The Challenge of Diversity. Indigenous Peoples and Reform of the State in Latin America. Amsterdam: Thela Thesis. 
Sieder, Rachel. (1996) Derecho consuetudinario y transición democrática en Guatemala. Guatemala: FLACSO.

Sierra, María Teresa. (Enero-junio de 1998) Autonomía y pluralismo jurídico: el debate mexicano. Revista América Indígena, VIII (1-2).

Sisco, Manuel. (2001) Despertar y uso de la palabra tradicional: cosmogonía y cosmovisión de la cultura nasa. Programa de Educación bilingüe, Consejo Indígena del Cauca.

Stavenhagen, Rodolfo y Diego Iturralde (editores). (1990) Entre la ley y la costumbre, el derecho consuetudinario indígena en América Latina. México: Instituto Indigenista Interamericano e Instituto Interamericano de Derechos Humanos.

Universidad Nacional de Colombia. (2000) Pensamiento Jurídico. Revista de teoría del derecho y análisis jurídico, 12, "Justicia Comunitaria" Parte I, Santafé de Bogotá, Unibiblos.

Uprimny Yepes, Rodrigo. (26 y 27 de abril de 2005) Justicia comunitaria en Bogotá: aproximación conceptual y reflexiones sobre su sentido político. En La Justicia, una construcción social para ser y hacer justicia ( $1^{\mathrm{a}}$ edición). Primer Encuentro Distrital de Justicia Comunitaria y Alternativa Memorias.

Bogotá: Gente Nueva Editorial.

Van Cott, Donna Lee. (2003) Pluralismo legal y Administración de justicia comunitaria informal en América Latina. Departamento de Ciencias Políticas Universidad de Tennesse, Knoxville.

Van Cott, Donna Lee. (2000) The Friendly Liquidation of the Past: The Politics of Diversity in Latin America.

Pittsburgh: University of Pittsburgh Press.
Van de Kerchove, Michel, et al. (2001) Elementos para una teoría crítica del derecho. Bogotá: Universidad Nacional de Colombia.

Villamil Ardila, Carol. (1997) ¿La justicia comunitaria: una oferta para la Paz? Una mirada urbana. Trabajo de grado (Abogado). Universidad Nacional de Colombia. Facultad de Derecho, Ciencias Políticas y Sociales. Programa interdisciplinario de Apoyo a la Comunidad (PRIAC).

Wolkmer, Antonio Carlos. (2003) Introducción al pensamiento jurídico critico. Bogotá: Instituto Latinoamericano de Servicios Legales Alternativos (ILSA).

Yrigoyen Fajardo, Raquel. (1999) Pautas de coordinación entre el derecho indígena y el derecho estatal. Guatemala: Fundación Myrna Mack. Recuperado de http://alertanet.org/antropryf-dc.htm

Yrigoyen Fajardo, Raquel. (2000) The Constitutional Recognition of Indigenous Law in Andean Countries. En Willem Assies et al. (eds.). The Challenge of Diversity. Indigenous Peoples and Reform of the State in Latin America. Amsterdam: Thela Thesis.

Zambrano Gómez, Sonia. (1990) La justicia popular en el municipio de la mesa Cundinamarca. Trabajo de grado (Abogado). Universidad Nacional de Colombia. Facultad de Derecho, Ciencias Políticas y Sociales. 